generally adheres to it. The under-surfaces of the ammonite and film are cleaned with benzolene and fragments of matrix removed. After drying, the specimen is placed film downwards on a glass sheet smeared 'with 'Vaseline'. A shellac film is painted on, and at the tacky stage a paper slip with registration number is affixed. When hard, the edges of the shellac are trimmed with a pair of scissors. Surface relief may be increased by treating the shellac surfaces with alcohol.

National Museum of Wales: Report for 1953-54

THE annual report for 1953-54 of the National Museum of Wales (pp. $63+4$ plates; from the Museum, Cardiff ; 1954) appears again in its new format and stresses the most urgent needs which were formulated by the Standing Commission in 1953. These include the erection of the western extension of the Museum and a museum block at the Welsh Folk Museum at St. Fagans. Although the first need remains in abeyance, a start has been made on the new Folk Museum at a cost of approximately $£ 15,000$. An "Exhibit of the Month" is now a regular' feature. This is arranged in turn by the departments concerned. 'The Department of Archæology reports a full programme of field-work. At Caerleon, Dr. V. E. Nash-Williams undertook the exploration of a five-acre site outside the Roman legionary fortress. A legionary civil settlement was proved, and datable material suggests that the buildings were in occupation from A.D. 100 to 300 or later. The site was also exceptionally rich in small finds. In addition to carrying out much extra-mural work of a character cognate to their normal museum tasks, the staff are responsible for an impressive list of publications.

\section{Science and the Press}

THE greater part of the March issue of the Atumic Scientists Journal is devoted to a symposium on science and the Press. The symposium included that part of Mr. L. J. F. Brimble's lecture to the Royal Society of Edinburgh in January 1954 which dealt with the interpretation of science; a contribution from Mr. L. Bertin, science correspondent of the Daily Telegraph, in which the position of the journalist is explained with clarity and understanding and the qualities demanded of a science writer are indicated; a discussion by Mr. Ritchie Calder of some causes of misunderstanding between scientific workers and journalists; and a summary by Dr. A. V. Cohen of the main points in a set of articles on the relations between scientific workers and the press contributed to the November 1953 issue of the Bulletin of the Atomic Scientists (U.S.A.). Mr. Calder's constructiv $\Theta$ article includes the statement that, in his opinion, a science editor should leave out, as scientifically dubious, scientific news which, for reasons of space, cannot be expounded or qualified, even though it may be prima facie of journalistic interest. He also stressed the difference between the presentation of scientific facts and helping people to understand the effects of scientific development. For satisfactory relations between scientific workers and the Press one condition is fundamental : the facts are inalienably the concerm of the man of science, but their treatment is the function of the scientific journalist, for which he is trained.

\section{Man's Role in Changing the Face of the Earth}

ThE Wenner-Gren Foundation for Anthropological Research, New York City, with the aid of the
National Science Foundation, Washington, D.C., is organizing an international symposium on "Man's Role in Changing the Face of the Earth", to be held during June 16-22 at the Princeton Inn, Princeton, N.J. Participation is limited to eighty invited experts, of whom seventeen are from outside the United States, representing India, Egypt, Israel, France, Belgium, Germany, Great Britain and Canada. The symposium will explore the question : What has been, and is, happening to the earth's surface as a result of man having been on it for a long time, increasing in numbers and skills in an uneven manner, with respect to place and time? The three main factors involved are: the earth's resources ; the numerical pressure of population upon, and sustained by, the resources ; and man's differing cultures, or ways of life. Fifty-two background papers, each reviewing some particular aspect and outlining the problems for future research, will be presented. Further information can be obtained from the organizer of the symposium, William L. Thomas, jun., Wenner-Gren Foundation, 14 East 7 lst Street, New York 21.

\section{Cold Spring Harbor Symposium on Population Genetics}

THE twentieth Cold Spring Harbor Symposium on Quantitative Biology will be held during June 6-13, the subject being "Population Genetics: the Nature and Causes of Genetic Variability in Populations". The object of the Symposium will be to bring leading workers together in an effort to establish an area of agreement on fundamental concepts common to both agricultural genetics and evolutionary genetics, and to this end the discussions will be focused on the following topics : general population genetics theory ; theory of quantitative genetics; selection in plants; selection in animals; genetic variability and polymorphism; populations in time and space; and integration of genotypes. The Symposium is open to all who are interested. Further information can be obtained from the Biological Laboratory, Cold Spring Harbor, New York.

\section{University of London}

THE following appointments have been made in the Imperial College of Science and Technology : Dr. J. McG. Bruckshaw, reader in geophysics in the College, to the University chair of applied geophysics; Prof. D. G. Christopherson, professor of mechanical engineering in the University of Leeds, to the University chair of applied science with special reference to engineering; Dr. Arthur Porter, head of the Research Division of Ferranti Electric, Ltd., Toronto, to the University chair of light electrical engineering.

Other appointments include the following: Dr. William Holmes, assistant in animal husbandry at the Hannah Dairy Research Institute, to the University chair of agriculture tenable at Wye College; Dr. J. G. Powles, I.C.I. Fellow in the University of Durham, to the University readership in experimental physics tenable at Queen Mary College; Dr. G. B. West, lecturer in pharmacology in the University of St. Andrews, to the University readership in pharmacology tenable at the School of Pharmacy.

\section{The Night Sky in May}

Full moon occurs on May 6d. 22h. 14m., U.T., and new moon on May 21d. 20h. 58m. The following 